\title{
Reflections on the development of contrastive domain of second language education: An overview
}

\author{
Masoud Mahmoodzadeh \\ Faculty of Foreign Languages, Sheikhbahaee University, Fereshteh St., Phase 1, \\ Baharestan, Isfahan, Iran \\ E-mail address: masoudmahmoodzadeh@yahoo.com
}

\begin{abstract}
ABSRACT
The current paper reflects on the evolving course and place of contrastive aspects of second language research. It attempts to give a concise overview of the related cross-linguistic perspectives over the last decades and elucidates their ascribed nuts and bolts in order to shed further light on the role and significance of cross-linguistic studies in second language research from the past up until now. To this end, the author expressly elaborates on different versions of Contrastive Analysis (CA) to come up with a clear picture of 'contrastive' genre of second language education. The paper concludes that notwithstanding of its inconsistent influence, the contrastive realm of second language education has firmly abided and has dynamically maintained its sphere of influence in L2 research.
\end{abstract}

Keywords: contrastive linguistics; contrastive analysis; second language education

\section{INTRODUCING CONTASTIVE RESEARCH IN SECOND LANGUAGE EDUCATION}

In the middle of the twentieth century, the priority of cross-linguistic research was notably stressed in second language education and soon because a core issue in the area of applied linguistics through the thought-provoking advent of Contrastive Linguistics $(C L)$ as a new well-founded disciple. Broadly defined, contrastive linguistics is the study of one or more languages, for applied or theoretical purposes (Johansson, 2000).

Following the adoption of the premises of CL, researchers and practitioners were endowed with numerous pedagogical insights and implications because the reported findings were essentials of language teaching in the prime life of structural linguistics, behavioristic psychology, and pattern practice language teaching methodologies such as audiolingual method (Brown, 2000; James, 1980). Another area where contrastive linguistics had a prime influence was in translation (Beekman and Callow, 1974; Enkvist, 1978). The goal was to help translators identify the differences between languages, with the goal of achieving better translations.

As Krzeszowski (1990) discusses, originally all contrastive studies were pedagogically motivated and oriented; however, some distinctions have been drawn between "theoretical" and "applied" contrastive studies. In this respect, Krzeszowski likewise contends that applied contrastive studies are distinct from theoretical contrastive studies; the former studies, as part of applied linguistics, "must depend not only on theoretical, descriptive, and comparative linguistics but also on other disciplines relevant to teaching including psycholinguistics, sociolinguistics, dialects, and psychology of learning" (pp. 10-11). 


\section{CONTRASTIVE ANALYSIS (CA) AND ITS ALTERNATIVE VERSIONS}

Contrastive Analysis (CA) known under the umbrella term of Contrastive Linguistics was shaped initially by the intellectual Zeitgeist of structuralism in linguistics and behaviorism in psychology (Danesi, 1995). The origins of CA in second language education go back to the 1950s, when it was mainly viewed as an applied discipline in the service of foreign language teaching (Gilquin, 2000). By definition, Richards and Schmidt (2002) concisely state that contrastive analysis is based on the following three maxims: "a) the main difficulties in learning a new language are caused by interference from L1; b) the difficulties can be predicted by $\mathrm{CA}$; c) teaching materials can make use of CA to reduce the effects of interference" (p.119).

In another sense, James (1980) advocates the attitude that CA is a hybrid which relies very strongly on psychology and linguistics because learning involves psychological processes. He likewise assigns CA to a science of applied linguistics for two reasons: firstly, because it is different from "pure linguistics" in drawing on other scientific disciplines; and secondly, because linguistics is the science upon which it draws most heavily. In essence, as Stern (1983) asserts, CA was not a new teaching method; but it was a form of language description applicable to language teachers, materials and curriculum developers, and test designers.

In the same vein, Keshavarz (1994) discusses that during the 1950s and 1960s, CA was considered as the ultimate panacea for language teaching problems: predicting and solving learners' errors and difficulties. As discussed by Larsen-Freeman (1991), before the emergence of SLA as a distinct field, researchers conducted contrastive analyses between the learners' L1 and L2 in order to anticipate areas of divergence which were likely to cause the learners difficulty and those of convergence where one could expect positive transfer. This practice was consistent with the then prevailing behaviorist view of language acquisition: learning by conditioning.

Based on the assumption that second/foreign language learners tend to transfer the formal features of their L1 to their L2 utterances, structural linguists set out to identify areas of difficulty for second language and produce appropriate teaching materials to overcome these linguistic obstacles. In effect, on the one hand, the task of a contrastive analyst was to pinpoint the items in learner's L1 which are in line with the similar items in learner's L2 (positive transfer) so as to facilitate language learning process.

On the other hand, the contrastive analyst identified the areas of asymmetry between the learner's L1 and L2 (negative transfer) and predicted the areas of learning difficulties and thus avoided the probable linguistic phenomenon of interference which was believed to seriously hinder the process of second language learning (Krzeszowski, 1990).

A number of fundamental and applied objectives have traditionally been attributed to CA: The first objective is discovering similarities and differences between languages. The second objective is explaining and predicting problems in L2 Learning. And the third objective is developing course materials for language teaching (Keshavarz (1994).

Notwithstanding the insights yielded for CA-based findings in the 1960s, with hindsight, the ascribed predictive axiom of $\mathrm{CAH}$ was severely criticized and called into question in the 1970s (e.g. Corder, 1973; Oller \& Ziahosseiny, 1970; Whitman \& Jacson, 1972; Wode, 1967). As a result, Wardhaugh (1970) termed the early version of CAH strong version and called for an alternative version of the early CAH called weak version in which $a$ priori prediction of certain linguistic items across languages was not claimed and the influence of learner's L1 system was emphasized instead of the predictive value of the learner's L1 system. According to Brown (2000), today the weak version of CAH can still be viewed under the general label cross-linguistic influence (CLI) (see Kellerman \& Smith, 
1986) which realizes the influence of the learner's native language as prior knowledge or experience on second language learning and teaching.

Moreover, drawing upon recent work concerning contrastive issues, Gilquin (2001) discusses that two approaches which go particularly well together are Contrastive Analysis (CA) and Contrastive Interlanguage Analysis (CIA) (see Granger, 1996 for comprehensive details regarding CIA premises). While the former compares two languages in order to come to a description of their differences and similarities, the latter tries to discover the features of nativeness and non-nativeness of learner language by comparing it with native language.

According to Taboada et al. (2012), the methodology of the above latter version is likewise adopted in most Computer Learner Corpora (CLC) research which may consist of two types of comparison: "a comparison of native language and learner language (L1 vs. L2) and a comparison of different varieties of interlanguage (L2 vs. L2)" (p. 4).

Likewise, some other invaluable attempts were made by L2 researchers so as to survey another unexplored aspect of contrastive agenda called 'concept'. In fact, the initial wave of innovative research in developing a functional CA based on conceptual analysis was launched in the 1960s, predating the birth of Contrastive Rhetoric Movement (Kaplan, 1966). A quick glimpse at the claim of this movement indicates that the occurrence of negative transfer is largely due to rhetorical conceptual elements rather than to purely lexical or syntactic elements (Chesterman, 1998; Connor, 1996, 2002; Danesi, 2003; Kaplan, 1978; Kroll, 1990; Leki, 1991).

Following the findings of the movement at issue, it was also found that conceptual errors were increasingly reported in learners discourse and interlanguage systems (see Danesi, 2000; Danesi \& Di Pietro, 1991; Robinett \& Schachter, 1983; Russo, 1997). Based on these significant corollaries, Danesi (2003) attempted to revitalize CA based on a conceptually-oriented model and introduced a revamped CA called conceptually-based $C A$. In this recently developed kind of $\mathrm{CA}$, the emphasis is given to the underlying conceptual structures reflected in language grammar, vocabulary, prosody, and so forth. According to Danesi (2003), within the crux of this contemporary view of CA lies our conceptual systems which are "culturally transmitted to us, through language, through our use and understanding of the language, and through other representational activities to which we are composed in a culture"(p. 91).

Over the last decades, however, most debates and attempts in Second Language Teaching (SLT) have been virtually directed towards the enhancement of linguistic and communicative competences whereas the conceptual competence has been taken for granted (see Talebinezhad, 2007; Talebinezhad \& Hashemian, 2006).

In effect, the lack of conceptual confidence in language learners is one of the most crucial factors accounting for vexing challenges in the circle of second language pedagogy which have ultimately led to the emergence of a kind of pedagogical quandary over the last decades called SLT Dilemma (see Danesi, 2003 \& also Mahmoodzadeh, 2011 for an in-depth synopsis of the issues).

Given the belief that conceptual competence is teachable and can be imparted in the classroom (see, for example Kaplan, 1966, Connor, 1996), Danesi (2003) likewise argues that

Conceptual competence is the ability of language learner to verbalize concepts so as to construct messages that have a culturally-appropriate structure, no matter what suitable syntactic or morphological form they assume. ...Conceptual competence consists of three main subcompetencies: metaformal, reflexive, and associative. Metaformal competence is the ability to use the conceptual system of a language appropriately in speech. Reflexive 
competence involves the ability to transform concepts into language categories (syntactic, morphological, etc.). Finally, associative competence is knowledge of how concepts are interconnected to each other in cultural term (pp. 75-76).

Some scholars, indeed, (e.g. Lakoff \& Johnson, 1980; Danesi, 1992; Talebinezhad and Hashemian, 2006; Talebinezhad, 2007) have suggested that our conceptual system is metaphorical in nature; and thus conceptual fluency is assumed to account for metaphorical competence. That is, L2 learners need to be exposed to metaphorical language to become conceptually fluent in the L2.

Thus, in a conceptually-based CA, following the identification of the main domains that allow native speakers to deliver this concept in discourse, language teachers, textbook designers, and syllabus designers can resort to the achieved results of the conceptual analysis to become aware of the areas of interconceptual interference and also intraconceptual interference (Danesi, 2003). Furthermore, Danesi (2003) claims that conceptual syllabuses "can be integrated with grammatical and communicative syllabuses but the core premises of the course and textbooks should revolve around concepts such as time, love, health, and etc." (p. 101).

Conceptually-based CA is directly related to the notions of conceptual competence and conceptual fluency. Unlike, Verbal fluency which is defined as the grammatical and communicative abilities of an L2 learner for producing discourse, conceptual fluency refers to the ability to use and comprehend the conceptual concepts of a given language (see Danesi, 2003 for further details). Thus, to be conceptually fluent in a language is to know how that language reflects or encodes its concepts on the basis of metaphorical structuring (Danesi, 1995; Danesi, 2003; Talebinezhad \& Hashemian, 2006).

Danesi (1993) claims that mastering only the linguistic structures never lead to high degree of proficiency among L2 learners. Based on his observation, the reason for such phenomena is that that these L2 learners have only developed verbal fluency while being in part deprived of conceptual fluency. Danesi (1995) also maintains that verbal fluency refers to as the grammatical and communicative ability of L2 learners to produce grammatical and communicatively appropriate discourse in an L2 leading to the achievement of linguistic and communicative competence whereas, conceptual fluency refers to the ability of L2 learners to comprehend and produce conceptually native-like structures in an L2.

Thus, it is essential to develop conceptual fluency to achieve a native-speaker competence. In this sense, Danesi (2003) discusses that a common observation of teachers is that students often produce L2 messages which are semantically anomalous when they attempt to speak or write spontaneously without some form of guidance. Danesi identifies the source of such anomaly in the unconscious tendency of learners to put together L2 messages on the basis of L1 concepts. Thus, the language teacher must ensure that the two systems: the linguistic and the conceptual are interrelated during all aspects and stages of instruction and practice.

In this respect, a conceptually-based CA can help language teachers to pinpoint the areas of difficulty. In fact, while dealing with incoming conceptual structures, the language teacher should attempt to apply the principle of conceptualization (Danesi, 2003) which plays a crucial role in the domain of second language teaching. This principle can manifest itself in one of these three ways: (1) it can be isomorphic(which of course rarely occurs), that is, L1 and L2 reflect the same conceptual structures ; (2) overlapping, that is, the conceptual structures have overlapping domains;(3) differentiated, that is, L1 and L2 reflect totally different conceptual structures. According to Colella (1999), 
If language itself may be seen as human - a container for the life experiences of a whole culture or people- then one cannot approach language teaching or even communication as a mathematical equation where $1+1=2$. Each word in the target language is represented by a sound: each sound is linked to a meaning and image/concept which may or may not coincide with the learner's L1 ( $p$. 142).

However, the metaphorical nature of a language is not only limited to conceptual domains but it has been demonstrated that grammatical structures also share this attribute. Consider, for example, the use of the Italian prepositions in and $a$ to indicate traveling to cities, regions, countries, or large islands. The Italian in/a can be contrasted to the English to, which not only does not share a similar dichotomy of containment, but also conceptualize traveling to a location as a mere matter of movement and directionality (see Danesi \& Mollica, 1998).

For the time being, however, it can be inferred that more studies need to be planned investigating the developed kind of CA, namely conceptually-based CA because this neglected type of CA obviously lacks sufficient research. By moving and approaching towards a conceptual approach, henceforth CA might prompt researchers to revisit the role of contrastive agenda in the area of second language research, provided that a consensus can be reached in this regard. This might likewise lead to a renewed interest in CA today, hopefully culminating in the revitalization of cross-linguistic research in order to achieve its heyday again after the lengthy decline of its traditional version in the 1970s.

\section{CONCLUDING REMARKS}

In this short paper, the researcher has attempted to track down the main route of crosslinguistic perspectives on second language research from the past till now in order to come up with an overview of the issues concerning cross-linguistic research. In a nutshell, after inquiring into the scholastic place and value of cross-linguistic studies in SLA and SLT, it can be inferred that the importance of cross-linguistic research need to be more recognized in the circle of second language pedagogy because its evolving trends have always permeated in second language education and have offered some insights to second language practitioners. So, the contrastive realm of second language education has firmly abided and has dynamically maintained its sphere of influence in second language research so far. Of course, as demonstrated above, the consistency of this influence has not been maintained and the circle of this influence has dynamically changed over the past decades. Danesi (1995), for example, argues that in the sixties and seventies, the association of CA to linguistic structuralism and psychological behaviorism became a stigmatic, as generative linguistics and cognitive psychology came to the forefront, but in the eighties, the interest in CA was somewhat rekindled by the possibility of extending its methodology into the area of pragmatics and cross-cultural analysis.

In the light of such contribution, it thus might be metaphorically concluded that up till now, the roots of cross-linguistic research in L2 research have virtually both thrived and withered from time to time, but never have died. 


\section{Biography}

Masoud Mahmoodzadeh is the author of several papers and state-of-the-art studies published in peer-reviwed educational journals. He is a member of the editorial board of several international journals. He has been an active member of the review board of several international journals as well. His main areas of interests include neurolinguistic studies; English language teaching methodology; ecological and cultural aspects of second language teaching; and complexity theory in SLA research.

\section{References}

[1] Beekman J., Callow J., Translating the Word of God. Grand Rapids, MI: Zondervan Publishing House, 1974.

[2] Brown H. D., Principles of Language Learning and Teaching (4 ${ }^{\text {th }}$ ed.). San Francisco State University: Pearson Education Limited, 2000.

[3] Chesterman A., Contrastive Functional Analysis. Amsterdam: John Benjamins, 1998.

[4] Colella C., Renzo Titone's Holodynamic Model for Language Behavior and Language Learning: Implications and Applications for the Second Language Teaching. Unpublished Doctoral Dissertation, University of Toronto, Canada, 1999.

[5] Connor U., Contrastive Rhetoric: Cross-cultural Aspects of Second-Language Writing. Cambridge: Cambridge University Press, 1996.

[6] Connor U., Tesol Quarterly 36 (4) (2002) 493-510.

[7] Corder S. P., Introducing Applied Linguistics. Middlesex: Penguin, 1973.

[8] Danesi M., Romance Language Annual 3 (1992) 189-194.

[9] Danesi M., Metaphorical competence in second language acquisition and second language teaching: The neglected dimension". In J. E. Alatis (Ed.), Language Communication and Social Meaning (pp. 234-254). Washington, D.C.: Georgetown University Press, 1993.

[10] Danesi, M., International Journal of Applied Linguistics 5(1) (1995) 3-20.

[11] Danesi, M., Semiotics in Language Education. Berlin: Mounton de Gruyter, 2000.

[12] Danesi M., Second Language Teaching: A View from the Right Side of the Brain. The Netherlands: Kluwer Academic Publishers, 2003.

[13] Danesi M., Di Pietro R. J., Contrastive analysis for the contemporary second language classroom. Toronto: OISE Press, 1991.

[14] Danesi M., Mollica A., Mosaic 5(2) (1991) 1-12.

[15] Elbow P., Writing Without Teachers. New York: Oxford University Press. (Appendix Essay: "The doubting game and the believing game: An analysis of the entellectual enterprise"), 1973.

[16] Elbow P., "The Believing Game--Methodological Believing". English Department Faculty Publication Series 5 (2008).

http://scholarworks.umass.edu/eng_faculty_pubs/5.

[17] Enkvist N. E., Contrastive text linguistics and translation. In L. Grühs, G. Korlén, B. Malmberg (eds), Theory and Practice of Translation (pp.169-188). Berne: Peter Lang, 1978. 
[18] Gilquin G., Languages in Contrast 3(1) (2000) 95-123.

[19] Granger S., From C. A., to CIA and back: An integrated approach of computerized bilingual and learner. In K. Aijmer, B. Altenberg and M. Johansson.(eds), Languages in Contrast. Languages in contrast (pp. 37-51). Lund, Sweden: Lund University Press, 1996.

[20] James S. D., Contrastive Analysis. London: Longman, 1980.

[21] Johansson S., Contrastive Linguistics and Corpora (Report from the project Languages in Contrast No. 3). Oslo: University of Oslo, 2000.

[22] Kaplan R. D., Language Learning, 16(1) (1966) 1-20.

[23] Kaplan R. D., Review of Applied Linguistics 39 (1978) 61-72.

[24] Kellerman E., Smith M. Sh. (Eds.). Cross-linguistic Influence in Second Language Acquisition. New York: Pergamon, 1986.

[25] Keshavarz M. H., Contrastive Analysis and Error Analysis. Tehran: Rahnama Press, 1994.

[26] Kroll B. (Eds.). Second Language Writing: Research Insight for the Classroom. Cambridge: Cambridge University Press, 1990.

[27] Krzeszowski T. P., Contrasting Languages: The Scope of Contrastive Linguistics. Berlin: Mouton de Gruyter, 1990.

[28] Lakoff G., Johnson M. Metaphors We Live By. Chicago: Chicago University Press, 1980.

[29] Larsen-Freeman D., TESOL QUARTERLY 25(2) (1991) 315-350.

[30] Leki I., TESOL Quarterly 25 (1991) 123-43.

[31] Mahmoodzadeh M., Theory and Practice in Language Studies 1(10) (2011) 1375-1382.

[32] Meihami H., Varmaghani Z., International Letters of Social and Humanistic Sciences 9 (2013) 49-58.

[33] Oller J. W., Ziahosseiny S., Language Leaning 20 (1970) 183-189.

[34] Richards J. C., Schmidt R., Longman Dictionary of Language Teaching and Applied Linguistics (3rd Ed.). Malaysia: Pearson Education Limited, 2002.

[35] Robinett B. W., Schachter J., Second Language Learning: Contrastive Analysis, Error Analysis, and Related Aspects. Ann Arbor: University of Michigan Press, 1983.

[36] Russo G. A., A conceptual fluency framework for the teaching of Italian as a second language. Unpublished Doctorial Dissertation. University of Toronto, Canada, 1997.

[37] Stern H. H., Fundamental Concepts of Language Teaching. Oxford: Oxford University Press, 1983.

[38] Taboada M., Doval Suarez S., Gonzalez Alvarez E., Linguistics and the Human Sciences 6 (2012) 1-16.

[39] Talebinezhad M. R., Journal of Social Sciences and Humanities of Shiraz University 26(4) (2007) 87-106.

[40] Talebinezhad M. R., Hashemian M., Iranian Journal of Applied Linguistics 9(1) (2006) 73-99. 
[41] Wardhaugh R., TESOL Quarterly 4 (1970) 123-130.

[42] Whitman R., Jackson K. L., Language learning 22 (1972) 29-41.

[43] Wode H., Working Paper in Bilingualism 11 (1967) 1-13.

( Received 04 November 2013; accepted 10 November 2013 ) 